\title{
The neuro-cognitive turn in cultural sociology: from 1.0 to 2.0
}

\section{Philip Smith ${ }^{1}$}

Published online: 8 February 2020

(c) Springer Nature Limited 2020

It is an intellectual move with familiar talking points. Social theory is full of vague concepts. It has been going nowhere for a long time, replaying tired debates and reinventing the wheel. In empirical research and all too rare efforts at actual explanation, understandings about causality are hopelessly muddled. The model of the human actor we have been working with is just plain wrong. We need to get back to basics and build knowledge in a more coherent way from the ground up. In other disciplines they do things better than we do. They have found truths, not endless debates, because they are scientists not sophists. We are behind the times. If only our research community could look up from wordy foundational texts by long dead figures and see the leading edge was no longer the year 1900, or 1950 or even 1980 - then we could all move on. Something like this spirit of renewal animated George Homans with his push for an atomized exchange theory and the identification of universal rules of social life. It was to replay in the "nuts and bolts' rational choice theory of the 1980s, in analytic Marxism, and in attempts at formal, mathematical sociology by James Coleman and Harrison White. The savior discipline was typically economics, but there have also been nods towards evolutionary biology, ethology, primatology, network science, complex systems modeling and leading-edge statistics.

In the case of the neuro-cognitive turn 1.0, something of this kind took place. But unlike those earlier purges, it was also a revolution from within. The leading practitioners such as Cerulo, DiMaggio, Lizardo, and Vaisey were well-grounded in cultural theory and had humanistic sensibilities. For them social life was about meaning, not just power or organization. The essential claim was that much could be learned from the experimental and physiological frontiers of psychology. Existing models of the actor and the action in sociology needed revision. We had been giving too much attention to conscious thought and cool deliberation rather than automatic gut reactions. We should be looking inward at brain function and the foundational

Philip Smith

philip.smith@yale.edu

1 Department of Sociology, Yale University, 493 College Street, New Haven, CT 06511-8933, USA 
neural mechanisms of human cognition rather than outwards at semiotic systems, discourses, and mythologies. Various fuzzy or missing links in the causal chains connecting meanings to actions could be filled in with the help of this new and more scientific knowledge coming from outside of sociology. The claims were bold, often brilliant but also evangelical, polemical, and somewhat divisive.

The collection here introduces phase 2.0 of the neuro-cognitive turn in cultural sociology. This is shown to be a far more nuanced and accommodating field. The texts and findings of leading psychologists are revisited and points of connection located for a conventional cultural sociology that has a vision of circulating meaning systems and collective actors. Claims are modified and scope conditions are spelled out. Where possible, common ground is located. For example, the 'gut reactions' that demonstrate instinctive prejudice in rapid response lab tests can be seen as evidence of the internalization of wider semiotic codes regarding race or gender. Socialization shapes brain shortcuts and these generate automatic responses and bias. Successful performances may well involve the triggering of mirror neurons, but for those neurons to be triggered the performance actually has to be a good one. Then we get 'fusion'. It is now argued that we should understand the importance of individual brains and choices but as real sociologists we should not overlook the 'collective cognition' of organizations, human-technology systems, and forms of traditional wisdom.

Put simply, there is more modesty. Peace is breaking out. The neuro-cognitive revolution has come of age.

Philip Smith

Co-Editor AJCS

Publisher's Note Springer Nature remains neutral with regard to jurisdictional claims in published maps and institutional affiliations. 